\title{
O USO DA METODOLOGIA ATIVA NO ENSINO DE ENGENHARIA CIVIL
}

DOI: 10.37702/2175-957X.COBENGE.2021.3683

Aparecida silva Santos carbone - cinda.carbone.pln@gmail.com

Unicamp

antonio pazetti 632

13140-741 - paulinia - SP

Letícia Peixoto - leh.peixoto@gmail.com

UNISAL

Osvaldo Anhert 550

13034-190 - Campinas - SP

Vinicius Rafael de Araujo Nogueira - vinicius.enge93@gmail.com UNISAL

Rua Francisco Fadim 520

13140-726 - Paulinia - SP

Adriana Aparecida Ambrósio de Souza - adriana.souza@unisal.br UNISAL

Av. Almeida Garret 267

13087-290 - Campinas - SP

LUCAS NAIF CALURI - lucasnaifcaluri@gmail.com

Unisal Centro Universitário salesiano de São Paulo

Rua Coelho Neto 331

13023-020 - Campinas - SP

Gabrielle Rohan Maués - gabii.rohan@hotmail.com

Centro Universitário Salesiano de São Paulo

Avenida Papa Pio XII 900

13070-903 - Campinas - SP

Resumo: $O$ presente trabalho tem por objetivo verificar a aplicação de metodologias ativas durante a realização de atividades práticas relacionadas ao curso de Engenharia Civil, através de uma análise comparativa, demonstrando que 
é possível desenvolver nos estudantes a autonomia e colocá-los como sujeitos ativos no seu processo de aprendizagem. A metodologia trata-se de aulas práticas, onde o participante é estimulado a desenvolver atividades que o remetem ao curso de Engenharia Civil. Este método proporciona aos discentes maior segurança e cognição ao atuar no mercado de trabalho. Portanto, conclui-se que esta metodologia de aprendizagem é uma nova trajetória para as instituições de ensino, possibilitando aulas interativas para melhor conhecimento dos estudantes.

Palavras-chave: Metodologias ativas de aprendizagem. Atividades práticas. Engenharia Civil. 


\title{
O USO DA METODOLOGIA ATIVA NO ENSINO DE ENGENHARIA CIVIL
}

\author{
The use of active methodology in the Civil Engineering teaching
}

\section{INTRODUÇÃO}

A metodologia ativa é uma concepção educativa que estimula processos de ensino-aprendizagem críticos-reflexivos, no qual o educando participa e se compromete com seu aprendizado. O método propõe a elaboração de situações de ensino que promovam uma aproximação crítica do aluno com a realidade; a reflexão sobre problemas que geram curiosidade e desafio; a disponibilização de recursos para pesquisar problemas e soluções; a identificação e organização das soluções hipotéticas mais adequadas à situação e a aplicação dessas soluções.

Segundo Martins, Estumano e Tavares (2015), a técnica mais utilizada no dia a dia das Instituições de Ensino Superior é aquela que se dá através de aulas expositivas, onde o conteúdo é transmitido no quadro pelos professores e transcritos pelos alunos no caderno, sendo considerada a metodologia de ensino mais tradicional dos últimos tempos, visto que o papel dos estudantes é apenas adquirir o conhecimento passado pelo educador.

Porém, o que realmente busca-se através do uso de metodologias ativas é a relação prática do aluno com a área de estudo, pois é evidente que a utilização de métodos de execução ativos formará profissionais mais capacitados e eficientes para o ambiente de trabalho, buscando a aproximação do estudante com a realidade enfrentada nas empresas. Assim, conforme Tidd\&Bessant $(2015$, p.4) "inovação é movida pela habilidade de estabelecer relação, detectar oportunidades e tirar proveito delas." Dessa forma, estabelecer métodos de aprendizagem que contribuem para o desenvolvimento de um aluno pode beneficiar todo o meio onde este está inserido.As metodologias ativas têm como objetivo a atuação do aluno frente a sua própria conquista de aprendizagem. As atividades favorecem o aluno em diversos aspectos, dando-Ihe características excepcionais não só para sua vida profissional, como também pessoal (DUMINELLI, 2017). A aplicação dessas metodologias ativas faz com que a relação entre o aluno e o professor se torne mais próxima, criando laços e interações mais eficazes.

A Engenharia Civil é uma área que apresenta uma vasta oportunidade no mercado de trabalho. Sendo assim, o uso da metodologia ativa torna-se mais acessível neste ramo, tendo em vista diversas atividades práticas e métodos de ensaio. Diante disso, o presente trabalho busca, por meio da análise comparativa, verificar a aplicação de metodologias ativas durante a realização de atividades práticas relacionadas ao curso de Engenharia Civil. As atividades serão realizadas embasadas nas disciplinas de Mecânica dos Solos e Topografia, ambas disciplinas do curso de graduação em Engenharia Civil.

\section{REVISÃO BIBLIOGRÁFICA}

\subsection{Metodologia ativa}

A metodologia ativa exerce a função de buscar atrativos em aprendizados teóricos comuns apresentados em sala de aula, elaborando métodos diferenciados para a aplicação de teorias, fazendo com que os alunos unifiquem a teoria com a prática, tornando-se assim alunos criativos. 
Adaptadas às exigências do mundo moderno, as metodologias ativas têm como característica principal tornar o aluno protagonista do seu próprio aprendizado, onde os papéis são invertidos em relação aos professores. Elas podem ser aplicadas em salas de aula que ainda são adequadas ao método tradicional de ensino, buscando incentivar que os estudantes desenvolvam a capacidade de absorção de conteúdos de maneira participativa e autônoma.

\subsubsection{Aprendizagem baseada em problemas (ABP)}

Segundo Araújo (2011), a Aprendizagem Baseada em Problemas (PBL) surgiu na década de 60, no Canadá, onde foi aplicada inicialmente em escolas de Medicina. Atualmente, tem sido utilizada nas áreas de administração, arquitetura, ciências da computação, ciências sociais, economia, engenharias e matemática.

O criador deste método foi Dewey, John (1859-1952), um filósofo que defendeu à ideia de unir a prática com a teoria. A ideia principal de sua teoria foi de que a melhor aprendizagem se dá por meio de vivências. A PBL é "uma metodologia de ensino-aprendizagem colaborativa, construtivista e contextualizada, na qual situações-problema são utilizadas para iniciar, direcionar e motivar a aprendizagem de conceitos, teorias e o desenvolvimento de habilidades e atitudes no contexto de sala de aula, isto é, sem a necessidade de conceber disciplinas especificamente para esse fim" (RIBEIRO, 2010, pág. 10).

\subsubsection{Metodologia da problematização (MP)}

A Metodologia da Problematização (MP) foi proposta, inicialmente, por Bordenave e Pereira e seu ponto de partida é o pensamento freireano, uma vez que leva em conta a realidade do sujeito (estudante), sua experiência e conhecimentos prévios. O método difundido por Bordenave e Pereira, em conexão com a pedagogia de Paulo Freire, tem sido a modalidade de MP mais comumente adotada no ensino superior (FREITAS, 2012) A MP utiliza-se de um esquema elaborado por Charles Maguerez denominado "Método do Arco".

A observação da realidade ocorre através da problematização dos alunos, onde não há restrições ao identifica-las, pois são encontradas na realidade social, dinâmica e complexa dos mesmos. Segundo Berbel (1998b), as pesquisas acontecem na fase da teorização, quando surgem as informações sobre os pontos chaves, onde os alunos se organizam para investigar informações sobre o problema e após isso identificam a ocorrência e confrontam sobre tal situação.

A hipótese de soluções define-se por resolução do problema. É a fase em que o aluno se questiona sobre o que é preciso ser feito para que haja soluções e quais são as alternativas para que isso aconteça. A última etapa é a aplicação à realidade, onde o estudante tem o compromisso com o seu meio, no qual ocorre a reflexão do mesmo com a prática a ser executada.

\subsubsection{Orientação por meio de projetos (OMP)}

A palavra projeto tem por seu significado planejar algo com a intenção de realizar. Os projetos nascem à medida da necessidade do ser humano de se desenvolver, através do interesse de uma pessoa ou até mesmo grupo de pessoas e organizações.

Os pioneiros deste método foram John Dewey e William H. Kilpatrick em meados do século XIX, porém teve seu ápice na Itália no século seguinte. Para Kilpatrick existiam quatro fases essenciais para o desenvolvimento do projeto, que são elas: 
intenção, planejamento, execução e julgamento. No método de aprendizagem por meio de projetos o educador interroga o aluno com uma pergunta que deixe - 0 intrigado para buscar soluções, desenvolvendo seu raciocínio e sua criatividade. $O$ método tem por protagonista o próprio aluno, onde faz com que o mesmo busque soluções para seu projeto a partir de sua curiosidade, fazendo que o aluno tenha espaço suficiente para se desenvolver.

\subsubsection{0 uso de metodologias ativas na engenharia}

Uma das maiores vantagens do uso de metodologias ativas no ensino de Engenharia é a diversidade de áreas de formação profissional que o mesmo oferece, tendo em vista maior facilidade na elaboração de aulas práticas. É o caso das aulas de laboratório, oficinas, tarefas em grupo, trabalhos em equipe dentro e fora do ambiente escolar, visitas técnicas e desenvolvimento de projetos.

De acordo com BONWELL (2008), as estratégias que podem ser utilizadas para se conseguir ambientes de aprendizagem ativa, destacam-se: debates sobre áreas de interesse profissional e temas da atualidade; tarefas colaborativas realizadas em equipe; estudo de casos em áreas profissionais; desenvolvimento de ideias para resolução de problemas; utilização de diagramas de gestão de informação para aprofundar conceitos e princípios; delineação e representação de processos e sistemas; criação de espaços virtuais para atividades coletivas; e programação de conteúdo de pesquisa científica e tecnológica. Portanto, é através da boa condução destas metodologias que ocorre a contribuição para a formação de ambientes ativos, proporcionando o envolvimento dinâmico do aluno no processo de aprendizagem.

\section{METODOLOGIA}

Para a realização deste artigo executou-se atividades praticas relacionadas ao curso de Engenharia Civil com alunos do ensino superior de duas universidades diferentes, ambos do mesmo período de aprendizagem. Através da realização das atividades práticas e a aplicação do Socrative espera-se criar um panorama a respeito da absorção de conhecimento pelos participantes observando seu aproveitamento durante a realização das oficinas. Durante a execução desta proposta realizou-se em sala de aula a apresentação do conteúdo teórico necessário para compreensão das atividades praticas. As atividades foram divididas em 3 etapas : apresentação do conteúdo teórico; execução da atividade pratica; resolução do socrative.

As oficinas realizadas englobaram conhecimentos referentes à disciplina de Mecânica dos Solos e topografia sendo executados os seguintes ensaios: Proctor Normal, CBR e Levantamento planimétrico e altimétrico.

\subsection{Ensaio}

As atividades em laboratório são de extrema importância para o ramo da construção civil, na qual os produtos e serviços são avaliados e testados de forma que garantam a qualidade e segurança da empresa, devido às exigências dos órgãos reguladores e fiscalizadores.

\subsubsection{Ensaio Proctor Normal}

A compactação é um método de estabilização de solos que se dá por aplicação de alguma forma de energia (impacto, vibração, compressão estática ou dinâmica). 
Seu efeito confere ao solo um aumento de seu peso específico e resistência ao cisalhamento, e uma diminuição do índice de vazios, permeabilidade e compressibilidade. Através do ensaio de compactação é possível obter a correlação entre o teor de umidade e o peso específico seco de um solo quando compactado com determinada energia. O ensaio mais comum é o de Proctor (Normal, Intermediário ou Modificado), que é realizado através de sucessivos impactos de um soquete padronizado na amostra.

\subsubsection{Ensaio CBR (Índice de Suporte Califórnia)}

O Índice de Suporte Califórnia (ISC ou CBR - California Bearing Ratio) é a relação, em percentagem, entre a pressão exercida por um pistão de diâmetro padronizado necessária à penetração no solo até determinado ponto $(0,1$ "e 0,2 ") e a pressão necessária para que o mesmo pistão penetre a mesma quantidade em solopadrão de brita graduada. Através do ensaio de CBR é possível conhecer qual será a expansão de um solo sob um pavimento quando este estiver saturado, e fornece indicações da perda de resistência do solo com a saturação. Apesar de ter um caráter empírico o ensaio de CBR é mundialmente difundido e serve de base para o dimensionamento de pavimentos flexíveis.

\subsection{Levantamento planimétrico e altimétrico}

O levantamento planimétrico e altimétrico visa determinar coordenadas $X, Y$ e $Z$ para conhecimento dos planos horizontais, verticais e relevos que constitui um determinado terreno. Executa-se este levantamento através de equipamentos topográficos como Estação Total. Através do uso do aplicativo Socrative aplicou-se questionários objetivos com os discentes participantes das oficinas realizadas, para assim avaliar a execução e participação nas atividades propostas. Permitindo assim que os discentes durante a aula prática executem os procedimentos conhecendo a teoria envolvida no processo.

\section{RESULTADOS E DISCUSSÃO}

Em preâmbulo uma aula introdutória foi executada para discernimento do manuseio dos aparelhos das oficinas juntamente com os conhecimentos teóricos necessários para sua realização. Posteriormente os estudantes colocaram em prática o desenvolvimento do ensaio visto em teoria, no que se refere às disciplinas de Mecânica dos Solos e Topografia. As oficinas foram realizadas com o intuito de colocar em pratica o conhecimento compartilhado em sala de aula. Durante a realização os participantes foram instigados a questionar os facilitadores quanto à realização dos ensaios. As oficinas foram realizadas em dias e locais distintos, conforme indica a tabela 1 abaixo.

Tabela 1: Cronograma das atividades.

\begin{tabular}{|l|l|}
\hline \multicolumn{1}{|c|}{ OFICINAS } & \multicolumn{1}{c|}{ LOCAL DAS ATIVIDADES } \\
\hline Proctor Normal - 25/08 & $\begin{array}{l}\text { Laboratório Unisal - Campus São José, Campinas- } \\
\text { SP. }\end{array}$ \\
\hline Proctor Normal - 31/08 & $\begin{array}{l}\text { Laboratório Unisal - Campus Dom Bosco, Americana- } \\
\text { SP. }\end{array}$ \\
\hline CBR - 09/11 & $\begin{array}{l}\text { Laboratório Unisal - Campus Dom Bosco, Americana- } \\
\text { SP. }\end{array}$ \\
\hline Levantamento Topográfico - 10/11 & $\begin{array}{l}\text { Laboratório Unisal - Campus São José, Campinas- } \\
\text { SP. }\end{array}$ \\
\hline
\end{tabular}




\subsection{Oficina Proctor Normal}

Os discentes divididos em grupos encontraram as bancadas organizadas para a realização do ensaio, sendo orientados quanto à importância de organização, conforme representado nas figuras 1,2 e 3 . Nesta oficina executou-se 0 ensaio Proctor Normal com a participação de 6 alunos da graduação de Engenharia Civil, 8은 Semestre da Faculdade Anhanguera de Jundiaí, São Paulo.

Figura 1, 2 e 3 - Organização da bancada.
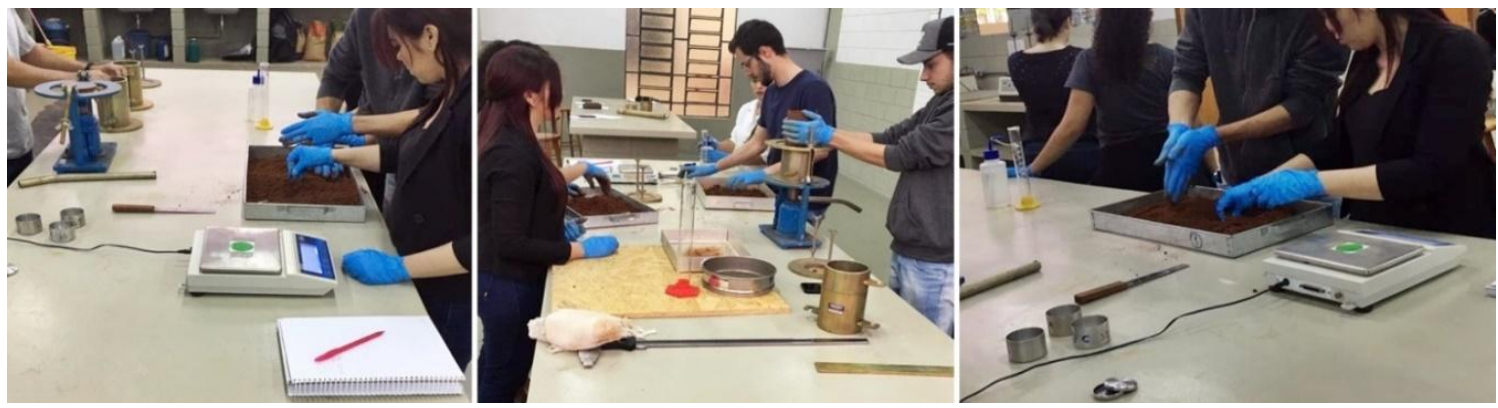

A figura 3 apresenta o processo de desterroar manualmente o solo antes do processo de compactação, para assim reduzir as partículas reduzindo os vazios existentes. Durante este processo observou-se que os discentes ficaram surpresos por terem literalmente que colocarem a mão na massa. Este método consiste na realização de diversas etapas que se não executadas com precisão interferem no resultado final.

A dificuldade encontrada inicialmente se deu por meio do contato dos discentes com os facilitadores, pois os mesmos estavam habituados com a metodologia passiva onde não havia este contato direto com o docente e com aparelhos, ressaltando que, estes alunos receberam apenas a teoria através do método online. Criando assim uma atividade participativa onde os discentes puderam questionar as etapas de execução e relacionar com o material lido nas aulas online.

\subsection{Oficina Proctor Normal}

A elaboração deste ensaio permite a aproximação dos alunos com os equipamentos através de processos manuais ou mecânicos. Esse tipo de procedimento exige maior atenção e cuidado no desenvolvimento, tornando-os mais cautelosos. No primeiro contato com os alunos foi possível identificar uma interação superior com os facilitadores e com os instrumentos mecânicos e manuais, pois os discentes encontram-se inseridos na instituição e estão habituados com este tipo de procedimento. As figuras 4, 5 e 6 apresenta-se o desenvolvimento do ensaio realizado com 6 alunos do $8^{\circ}$ semestre do curso de Engenharia Civil do UNISAL Campus Dom Bosco, em Americana, São Paulo.

Figura 4, 5 e 6 - Desenvolvimento do Ensaio Proctor Normal.

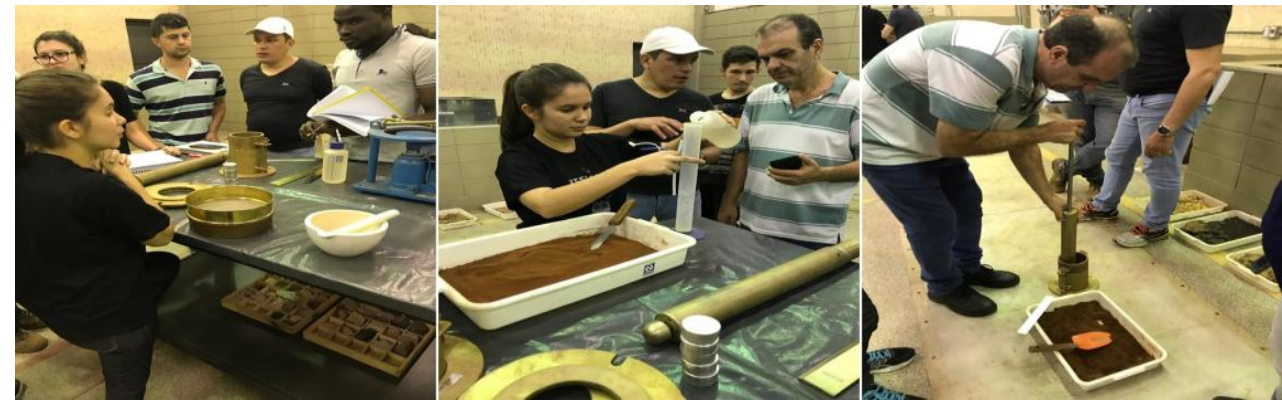


As figuras apresentadas acima demonstram as etapas do ensaio Proctor Normal, ou seja, primeiramente foi disponibilizada uma porção de amostra de solo para os discentes, onde passou por um processo de peneiramento para que a mesma ficasse homogênea e livre de torrões. Após isso foi necessário que a amostra fosse umedecida gradualmente, onde posteriormente foi lançada até um cilindro. Em seguida, com o soquete, aplicou-se 26 golpes na amostra disponibilizada no cilindro, de modo que a amostra estivesse compactada.

O obstáculo encontrado durante a realização desta oficina se deu por meio do questionário aplicado pelos facilitadores após a execução do ensaio, pois os mesmos não estavam acostumados a serem avaliados neste tipo de atividade. Habitualmente estes participantes utilizam o laboratório na disciplina de Mecânica dos Solos sendo perceptível ao término do ensaio a organização da banca e os cuidados com a limpeza do material utilizado. Todos os participantes da oficina responderam o questionário avaliativo demonstrando a aquisição do conhecimento praticado, muitos optaram por responder o questionário via plataforma instalada em seus celulares. No entanto, os graduandos mostraram interesse e disposição mesmo com as dificuldades apresentadas, colaborando com o rendimento e resultados da oficina.

\subsection{Oficina CBR}

Sendo um dos ensaios mais utilizados em pavimentação, o CBR torna-se mais atrativo aos educandos devido à diversidade de técnicas e aplicações. O desenvolvimento do ensaio CBR foi aplicado aos alunos do UNISAL, porém nesta oficina contou-se com a presença de 29 alunos. As figuras 7, 8 e 9 a seguir, representam o desenvolvimento desta atividade.

Figura 7, 8 e 9 - Desenvolvimento do Ensaio CBR
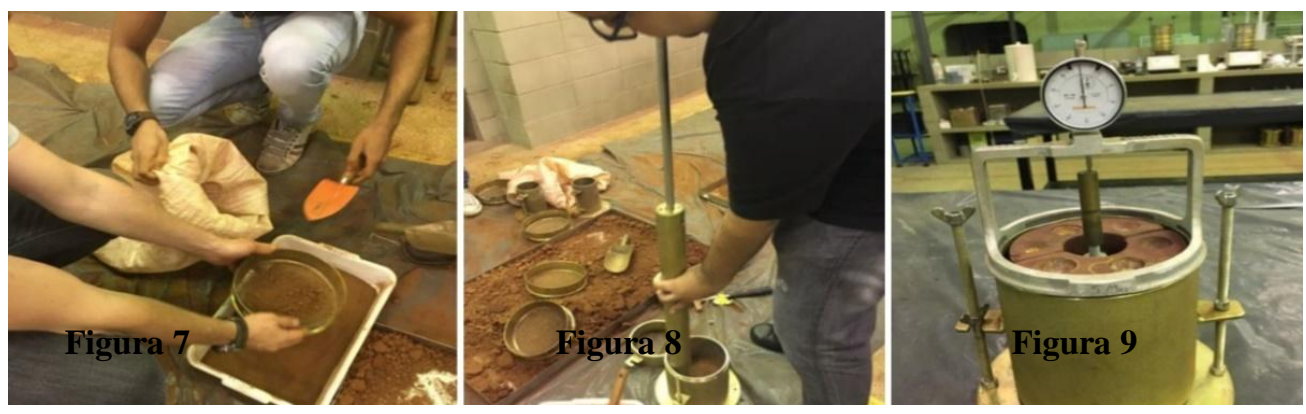

A execução deste ensaio envolve três etapas, onde estas devem ser executadas minuciosamente para que não haja a possibilidade de acumulo de erros. Observouse que os discentes estavam apreensivos quanto à execução, então os facilitadores interagiam elucidando as dúvidas.

\subsection{Oficina topografia}

As aulas práticas em Topografia são de suma importância, pois os discentes conseguem unir o que se aprendeu na teoria. Portanto, é uma maneira de vivenciar a realidade profissional e lidar com os conhecimentos topográficos em um nível empírico, obtendo mais segurança na execução de atividades exigidas nessa área.

A atividade iniciou-se por meio de uma aula introdutória de utilização dos equipamentos topográficos e como deveriam ser manuseados. Nesta atividade foi 
possível identificar uma boa dinâmica e trabalho em equipe realizada em campo pelos alunos, pois este método exige à colaboração e empenho de dos discentes e de seus orientadores. Além de esta aula ser realizada em campo ao ar livre, observa-se que os discentes interagem mais e buscam atentamente absorver as informações que foram apresentadas pelos facilitadores. O desenvolvimento do ensaio topográfico foi realizado novamente com os estudantes da Faculdade Anhanguera de Jundiaí, São Paulo, conforme apresentado nas figuras 10, 11 e 12.

Figura 10, 11 e 12- Desenvolvimento do Ensaio Topográfico.

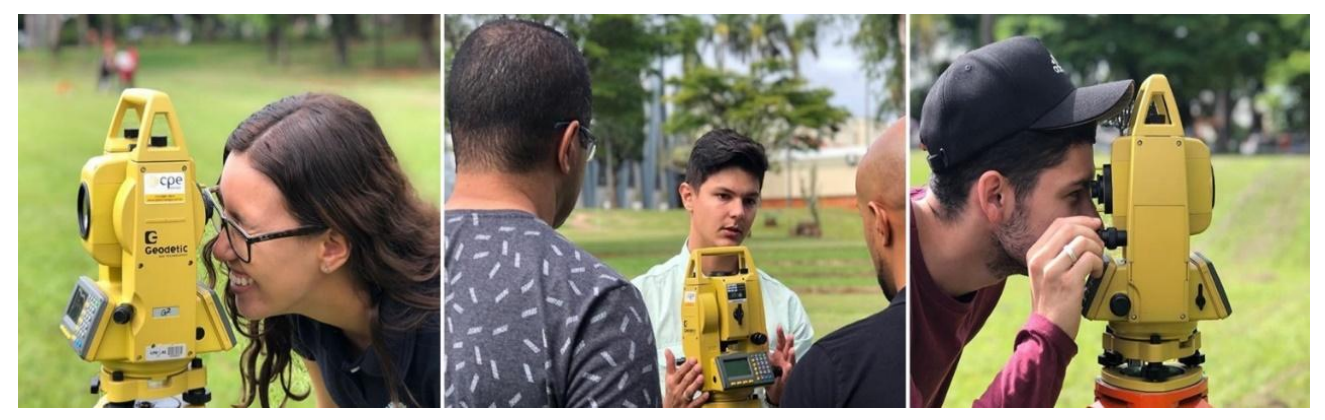

Esta oficina topográfica foi realizada no UNISAL Campus São José em Campinas, São Paulo. Na figura 15 observa-se o facilitador instruindo os discentes quanto à realização do levantamento. Este era o primeiro contato destes discentes com os equipamentos utilizados para levantamento topográfico, sendo motivo de muitos questionamentos sobre seu uso e procedimentos. Os alunos demonstraram entusiasmo e curiosidade durante a execução deste ensaio, visto que a atividade apresenta inúmeros procedimentos e complexidades. Uma das dificuldades encontradas pelos discentes foi o manuseio do equipamento Estação Total juntamente com os cálculos envolvidos, no entanto a presença dos facilitadores foi um ponto fundamental, pois estes iam elucidando as dúvidas.

\subsection{APLICAÇÃO DO SOCRATIVE}

Através do uso do aplicativo Socrative, aplicou-se questionários objetivos com os discentes participantes das oficinas realizadas, para assim avaliar a execução e participação nas atividades propostas.

O aplicativo Socrative permitiu assim que os discentes durante a aula prática coloquem a mão na massa e conheça a teoria envolvida no processo

A aplicação destes questionários avaliativos foi executada de forma interativa com os discentes após o término de cada atividade prática, ocorrendo através do método online, onde os orientadores disponibilizaram um computador portátil para tal resolução do questionário, e outros utilizaram seus próprios dispositivos móveis.

O obstáculo encontrado na realização destes questionários foi administrar o tempo que os discentes possuíam para responder o questionário, visto que ao término da aula prática era aplicado o questionário de imediato, não disponibilizando um tempo hábil para este processo. Outra dificuldade apresentada foi de que os alunos se mostraram retraídos ao serem avaliados, devido ao fato de realizarem a prática e logo em seguida responderem a um questionário teórico. $\mathrm{Na}$ primeira oficina de Proctor Normal, o questionário era composto por quatro perguntas 
relacionadas ao ensaio e duas questões avaliativas sobre a oficina. Através dos resultados obtidos pelas avaliações, foi possível identificar uma média de $97,17 \%$ de desempenho, conforme indica o gráfico 1 abaixo.

Gráfico 1: Desempenho Alunos I Oficina - Ensaio Proctor Normal.

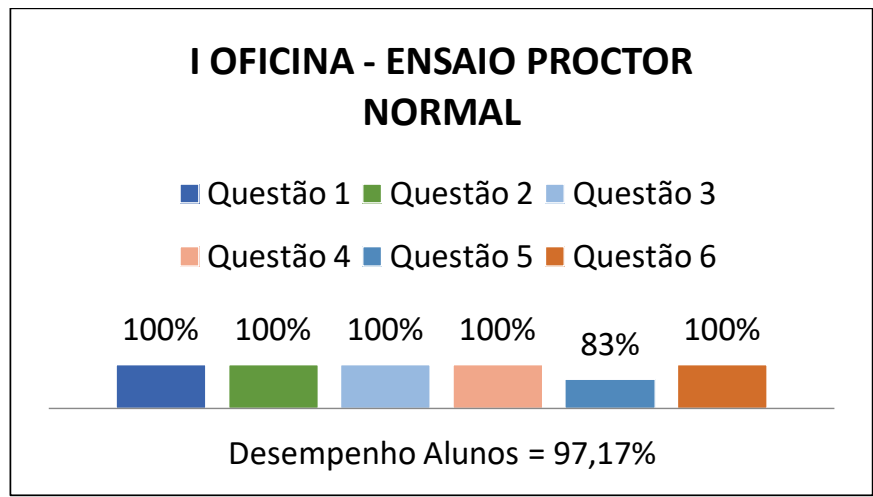

Ao observar a questão 5 , os discentes participantes tiveram como resultado final de $83 \%$ de aproveitamento, visto que a questão se referia à quantidade de amostras de solo utilizada, percebeu-se que a dificuldade encontrada foi recordar quantias, diferentemente das outras questões que se referiam ao procedimento que os discentes acabara de realizar.

Posteriormente, fora realizado a segunda oficina do ensaio Proctor Normal utilizando-se o mesmo questionário avaliativo anterior, no entanto, foram obtidos resultados distintos, conforme representa o gráfico 2 .

Gráfico 2: Desenvolvimento Alunos II Oficina - Ensaio Proctor Normal.

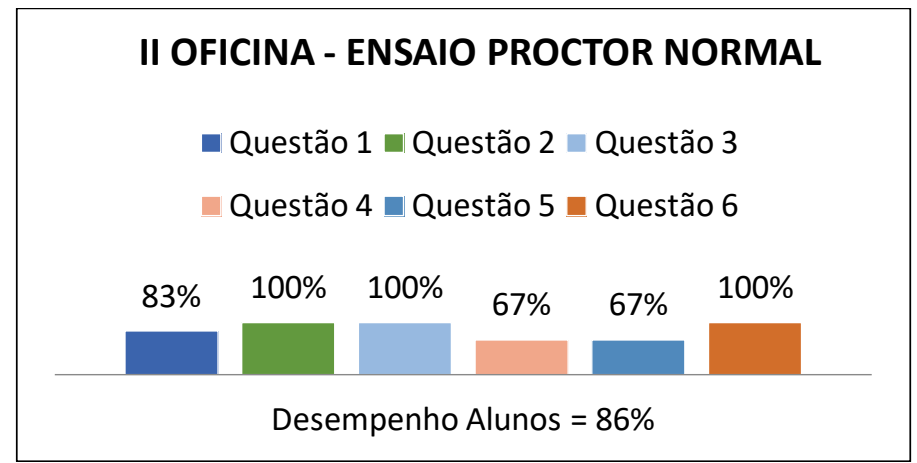

Os resultados desta pesquisa foram considerados satisfatórios, no entanto, conclui-se que o desenvolvimento dos alunos com o ensaio Proctor Normal foi de $86 \%$ de aproveitamento. O menor resultado foi apresentado nas questões 4 e 5 com $67 \%$ de rendimento, visto que as duas questões se referiam a quantias relacionadas aos procedimentos do ensaio, nesse caso composto por 3 amostras de solos, demostrando que os discentes não se atentaram a esta quantidade. Na questão $1 \mathrm{com} 83 \%$ de aproveitamento, tratava-se de uma pergunta sobre a opinião do aluno em relação a oficina, onde apenas 1 aluno classificou a oficina de maneira negativa. Por fim, as demais questões apresentaram um desempenho de $100 \%$. Em seguida, na oficina de CBR, o questionário era composto por duas questões de múltipla escolha e uma dicotômica. O interessante neste procedimento foi à evolução do número de alunos interessados e o desempenho eficaz dos mesmos, conforme indicado no gráfico 3 . 
Gráfico 3 - Desempenho Alunos I Oficina - Ensaio CBR.

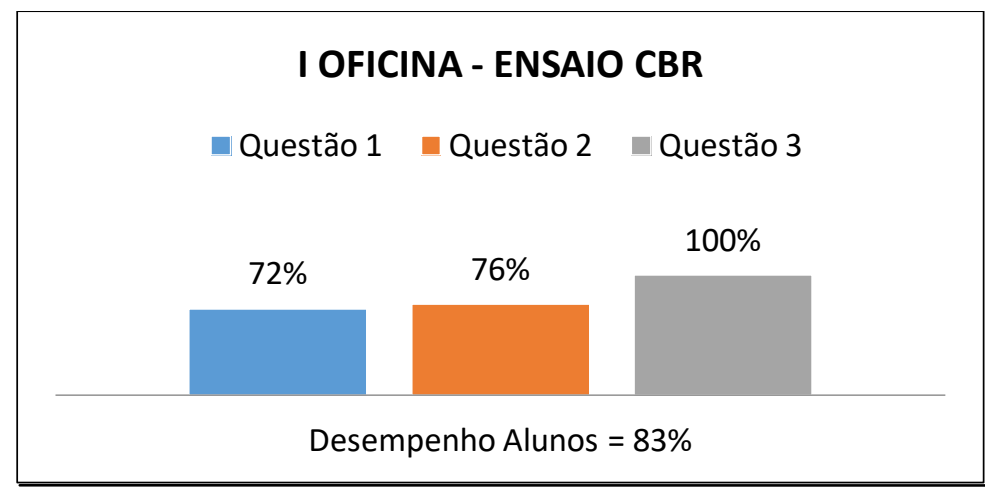

Complementa-se que o desenvolvimento dos alunos com o ensaio CBR foi de $83 \%$ de rendimento, ressaltando que os mesmos não receberam a aula teórica no mesmo dia do desenvolvimento do ensaio. No entanto, o menor resultado apresentado nesta atividade foi na questão1 com $72 \%$ de aproveitamento, pois a mesma indicava a teoria do ensaio realizado, onde os alunos apresentaram dificuldades em responder. A outra questão que revelou menor desempenho foi a 2 , tendo um aproveitamento de $76 \%$, onde os discentes se mostraram confusos ao identificar qual seria a classe do Proctor que está relacionada com o ensaio CBR. $\mathrm{Na}$ $3^{a}$ e última questão os graduandos não encontraram dificuldades, obtendo um aproveitamento de $100 \%$.

A última oficina a ser realizada foi a de Topografia, aplicando-se um questionário com cinco questões alternativas, onde os alunos responderam conforme a prática aplicada. Por seu dinamismo, esta atividade apresentou uma maior quantia de alunos entusiasmados e curiosos para a sua realização, sendo evidenciado nos resultados satisfatórios. Em relação aos instrumentos topográficos e o trabalho em campo, o ensaio apresentou maior repercussão entre todos os outros, devido ao fato dos discentes estarem habituados somente com a sala de aula. Os resultados mostraram-se eficazes, de acordo com o gráfico 4 apresentado a seguir.

Gráfico 4: Desempenho Alunos I Oficina - Ensaio Topográfico.

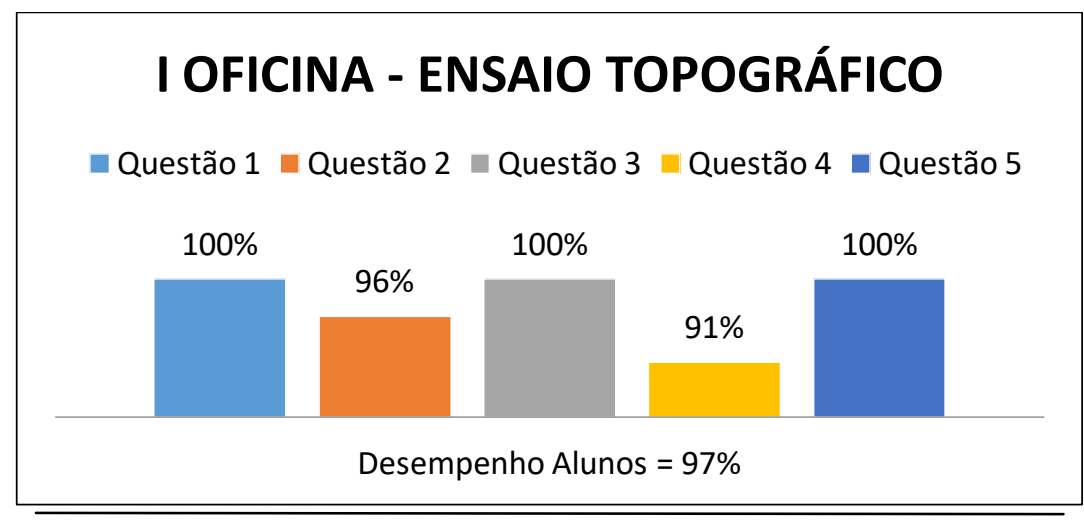

Sendo assim, conclui-se que o desenvolvimento dos discentes em Topografia foi de $97 \%$ de progresso. O menor desempenho foi identificado na questão 4 com $91 \%$ de rendimento, sendo que apenas 2 alunos não se atentaram em qual seria 0 primeiro passo para iniciar o ensaio. Na questão 2 também foram apresentado resultados inferiores com aproveitamento de 96\%, sendo identificado que 1 aluno apresentou dificuldade em unir a teoria aplicada na aula introdutória com a prática 
realizada em campo. Por fim, as outras questões tiveram 100\% de desempenho, não havendo obstáculos para que as mesmas fossem solucionadas.

\subsection{Avaliação de oficinas}

Os resultados das oficinas de metodologias ativas ocorreram positivamente conforme o planejado, sendo que em um total de 4 oficinas, totalizando 65 alunos, a média de desempenho alcançado pelos discentes foi de $90,8 \%$, conforme gráfico 5 abaixo.

Gráfico 5: Desempenho Alunos - Metodologias Ativas.

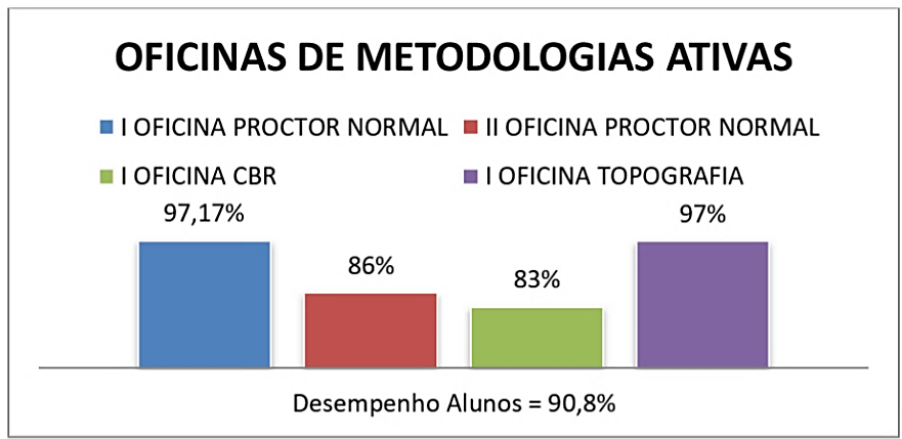

Visualiza-se que a I Oficina de Proctor Normal e a I Oficina de Topografia apresentaram maior desempenho na pesquisa, devido ao fato de que esses participantes tiveram a teoria como uma aula introdutória acompanhada com a prática no mesmo dia, ou seja, a união entre ambas às metodologias favorece a absorção de conteúdos. No entanto, na II Oficina de Proctor Normal e na I Oficina CBR os resultados foram inferiores, pois estes discentes tiveram contato com a teoria dias antes das atividades práticas, ou seja, não absorveram o conteúdo necessário para a unificação dos métodos avaliativos.

Ressalva-se que os alunos do $8^{\circ}$ semestre de Engenharia Civil da Faculdade Anhanguera de Jundiaí, tiveram acesso às metodologias passivas (método tradicional de ensino) apenas por educação a distancia, ou seja, através do portal do aluno (AVA). No entanto, vale ressaltar o obstáculo em desenvolver uma disciplina à distância, pois os mesmos não tinham a oportunidade de ter acesso à metodologia ativa presencial, sendo esta, a forma mais eficaz de aprendizado, devido ao método aplicativo onde a troca educador-discente ocorre. Portanto, identifica-se que os alunos da Faculdade Anhanguera tiveram um desempenho satisfatório, mesmo com a falta de acesso às atividades práticas, acreditando-se que estes discentes teriam resultados inferiores sem a aplicação da metodologia ativa.

Em relação aos alunos do $8^{\circ}$ semestre de Engenharia Civil do Unisal Campus Dom Bosco de Americana, os mesmos apresentaram desempenho satisfatório, visto que estes discentes tiveram acesso à aula presencial passiva, onde a professora aplicava o conteúdo em sala de aula através do método tradicional, e os alunos eram apenas reprodutores de informações.

Por fim, foi visto que todos os participantes apresentaram autonomia e segurança na execução, colocando em prática o que é visto através do método teórico de ensino, deixando de ser apenas um agente passivo e passando a ser um membro ativo na construção do saber.

\section{CONSIDERAÇÕES FINAIS}


O presente trabalho teve como intuito preparar os alunos para que pudessem aprender na prática sobre as disciplinas em questão, ampliando seu conhecimento para o mercado de trabalho, porém a metodologia ativa mesmo não tendo como foco, permite também aos professores adaptarem-se com novas técnicas, inovando as aulas fazendo com que sua sala fique mais interativa. No entanto, visualizou-se uma absorção eficaz de conteúdos em relação aos alunos do ensino superior com a metodologia ativa aplicada.

O uso da metodologia ativa utilizada em oficinas laboratoriais proporcionou aos alunos uma visão do seu aprendizado no cotidiano, fazendo com que o aluno possua maior interesse em aprender. Os estudantes demonstraram entusiasmo e interesse nas oficinas, facilitando a aprendizagem dos mesmos.

Ao comparar a metodologia ativa em relação à metodologia passiva, permitiu-se observar um melhor desempenho na metodologia ativa, onde os alunos apresentaram melhor capacidade de absorção de informações, tirando dúvidas e mostrando-se interessados, criando assim, laços mais efetivos com os seus professores e orientadores.

Conclui-se então, com resultados satisfatórios, onde os discentes demonstraram uma excelente absorção de informações e uma maior interação com o seu orientador. As atividades práticas alcançaram uma boa aceitação pelos discentes e pelos facilitadores, mesmo com as dificuldades em administrar as equipes, organizar os equipamentos e ministrar o tempo com a quantidade de alunos que desenvolveram as atividades.

Por fim, acredita-se que a metodologia ativa possa ser um novo caminho para instituições, seja ela para ensinos superiores ou para ensinos preparatórios, modificando o modo de aplicação das aulas e deixando-as interativas para melhor aprendizagem dos discentes.

\section{REFERÊNCIAS BIBLIOGRÁFICAS}

ARAÚJO, Ulisses F. Aprendizagem baseada em problemas no ensino superior. São Paulo: Summus, 2009. 18 p.

BARBOSA, Eduardo Fernandes; MOURA, Dácio Guimarães. Metodologias ativas de aprendizagem

no ensino de engenharia. In: COPEC - Conselho de PesquisasemEducação e Ciência: XIII International Conference on Engineering and Technology Education. 2014. p. $110-116$.

BARROWS, H. S. A Taxonomy of Problem-Based Learning methods. Medical Education, v.20, p. 481-486, 1986.

BENDER, William N. Aprendizagem baseada em projetos: Educação Diferenciada para o século XXI. Porto Alegre: Penso. 2014. 156 p.

BERBEL, N. N. A problematização e a aprendizagem baseada em problemas: diferentes termos ou diferentes caminhos? Interface - Comunicação, Saúde, Educação. v.2, n.2. 1998. 
BERBEL, N.A.N; A metodologia da problematização com o Arco de Maguerez: uma perspectiva teórica e epistemológica. Filosofia e Educação, ISSN 19849605. 2012; 3: № 2.

BONWELL, C, "Active learning: creating excitement in the classroom", Eric Digests, Publication Identif. ED340272, 2008

BORDENAVE, J. ; PEREIRA, A. Estratégias de ensino aprendizagem. 4. ed., Petrópolis: Vozes, 1982.

CAPUTO, Homero. Mecânica dos solos e suas aplicações.6a.ed. Rio de Janeiro: LTC, 1996. 334 p.

CASTRO, Elton; GONÇALVES, Jadir; BESSA, Sônia. Aplicação da metodologia de problematização. Goiás: UEG - Universidade de Goiás. 2017. 13 p.

DUMINELLI, MelineVitali; APLICABILIDADE DE METODOLOGIAS ATIVAS NOS MÉTODOS TRADICIONAIS, VISANDO A INOVAÇÃO NA APRENDIZAGEM NO ENSINO SUPERIOR. Foz do Iguaçu: Ciki, 2017. v. 7, p. 45 - 6

LAMBROS, A. Problem-Based Learning in K-8 Classrooms - A Teacher'sGuidetolmplementation. Thousand Oaks: Corwin Press, Inc. 2002.

MARTINS, H. S.; ESTUMANO, K. C.; TAVARES, D. M. L. Aplicação do Servqual na Definição dos Fatores Críticos de Sucesso de uma IES Privada no Brasil. In: Encontro Nacional de Engenharia de Produção, 35., 2015, Fortaleza. Anais. Fortaleza: Abepro, 2015.

RIBEIRO, Luis Roberto de Camargo. Aprendizagem Baseada em Problemas (PBL). São Carlos: EdUFSCar, 2010.151f

SEVERINO, A.J. Metodologia do trabalho científico. 23를 Ed. São Paulo: Cortez, 2007

Abstract:The present work aims to verify the application of active methodologies during the accomplishment of practical activities related to the Civil Engineering course, through a comparative analysis, demonstrating that it is possible to develop in students the autonomy and turn them into active people in their learning process. The methodology is about execution classes, which the participant is encouraged to develop activities that refer to the Civil Engineering course. This method provides students with greater security and cognition when working in the job market. Therefore, it is concluded that this learning methodology is a new trajectory for educational institutions, enabling interactive classes to understand the students better.

Keywords:Active learning methodologies. Pratical activities. Civil Engineering. 